\title{
Musculoskeletal neck and back pain in undergraduate dental students at a UK dental school - a cross-sectional study
}

\author{
S. Vijay' and M. Ide*1
}

\section{In brief}

Provides an understanding of the frequency and nature of muscloskeletal problems in UK dental students.
Describes possible ways forward to help manage and prevent such problems.

Objective Limited data exist on musculoskeletal problems within dental students: we aimed to determine the prevalence of these disorders. Design Single centre cross-sectional study. Setting A UK Dental School 2015. Methods Students completed a modified Nordic pain questionnaire. Main outcome measures Self-reported frequency and severity of pain, fitness and coping strategies. Results $63 \%$ of 390 respondents were female and $75 \%$ aged under 23 . Seventy-nine percent experienced pain with $42 \%$ experiencing pain for 30 or more days in the past year. Lower back pain was most common $(54 \%)$ and was most frequently the worst area of pain (48\%). Thirty-six percent reported pain lasting at least four hours. The mean 'average pain intensity' VAS score was 3.81/10 ( $(\mathrm{d}=1.75)$ and mean 'worst pain intensity' was $5.56(\mathrm{sd}=2.10)$. More females reported neck pain $(58 \%$ versus $37 \%, \mathrm{P}<0.001)$ and higher 'average pain intensity' (mean 4.02 , sd 1.82 versus $3.43 \mathrm{sd} 1.55, \mathrm{P}=0.012$. Daily stretching was used by $55.7 \%$ of respondents, and this positively correlated with 'average' and 'worst pain intensity' $(P=0.096$ and $P=0.001)$ scores. Eighteen percent sought professional help to manage pain. Conclusion Musculoskeletal pain is a problem for dental students. Education in self-care may be helpful; however, assessments of possible interventions are needed.

\section{Introduction and objective}

Musculoskeletal pain is one of the most significant occupational health hazards for healthcare professionals. ${ }^{1}$ Dentistry, particularly general dentistry, is considered to be one of the highestrisk professions for developing these problems, primarily due to high visual demands that result in prolonged static positions being adopted by clinicians, with movements being limited to the hand and wrist. ${ }^{2}$ A number of other factors have also been cited as contributing to the development of musculoskeletal pain including: sub-optimal lighting, genetic predisposition,

'King's College London Dental Institute, Periodontology/ Oral and Mucosal Biology, Floor 21, Tower Wing, Great

Maze Pond, London, SE1 9RT

${ }^{*}$ Correspondence to: Mark Ide

Email: mark.ide@kcl.ac.uk

Refereed Paper. Accepted 18 July 2016

DOI: 10.1038/sj.bdj.2016.642

${ }^{\oplus}$ British Dental Journal 2016; 221: 241-245 age, fitness and repetitive movements. ${ }^{3}$ The cumulative physiological damage of musculoskeletal pain is significant and has been shown to contribute considerably to reduced productivity, increased absence and clinicians leaving the profession. ${ }^{4}$

A systematic literature review of musculoskeletal disorders amongst dental professionals ${ }^{5}$ has suggested that the reported prevalence of general musculoskeletal pain amongst dentists varies between $64 \%$ and $93 \%$, with the most commonly cited regions of pain being the back (36.3-60.1\%) and neck (19.8-85\%). This review also suggested that there is a lack of research available into the prevalence of these issues amongst dental students, and with the pressure of tertiary education alongside the physical burden of clinical training, the question of whether neck and back pain arises during dental training should be further investigated. The impact of musculoskeletal disorders on practitioners is of further importance given current thinking that many of these problems are more a reflection of a functional disorder with minimal direct structural damage, which is much more likely to respond well to appropriate non-invasive management and coping strategies with good long term outcomes. It is not improbable that whilst practitioners do experience problems, many either adapt or find ways to manage their problems ${ }^{4}$ with only a few ultimately being forced to consider other career options.

The aim of the present study was to determine the prevalence, distribution and impact of the symptoms of musculoskeletal pain amongst current undergraduate dental students at a dental institute.

\section{Subjects and methods}

A cross-sectional study was conducted to assess the prevalence of musculoskeletal disorders amongst current undergraduate dental students at a UK dental institute. A total of 398 dental 
students from those attending lectures delivered during each year of the BDS programme anonymously completed a paper-based questionnaire quantifying their experience of upper back, lower back and neck pain.

The questionnaire used was a modified version of the Nordic Back Pain questionnaire. ${ }^{6-10}$ This was adapted to include some further questions related to demographics, as well as the self-reported use of loupes with or without illumination, levels of fitness and exercise, the use of various strategies to help address the problem and the impact of pain on ability to perform dental procedures. Students were offered further support if this problem was having a significant impact on their overall health and quality of life. All students were reminded and advised of pre-existing pastoral support services and were also invited to contact MI or other members of local and college support teams if they had concerns.

Results were entered by hand onto a spreadsheet then converted for analysis using Stata 11 software (College Station, Texas). Fifty sets of results were selected and rechecked for accuracy in transposition - no errors were identified. The distribution of variables was assessed to determine appropriate statistical tests. Outcomes of interest included the general demographic variables of population, including use of magnification with or without illumination and self-reported levels of fitness and exercise; the prevalence, pattern and impact of pain from neck and upper and lower back regions; the frequency, intensity, impact and attempted coping strategies for each participant's most intense problem; relationships between the demographics outlined above and the prevalence, impact and intensity of self-reported pain.

This study was approved by the King's College London Research Ethics Committee, Reference Number: BDM/13/14-113.

\section{Results}

\section{Demographics and behaviour}

The demographic characteristics of respondents are shown in Table 1. The total number of students potentially available by attending lectures was 740. In total, 398 (54.8\%) of those attended lectures during the recruitment phase and returned questionnaires, although 8 of these were not completed and so were excluded from the analysis, giving a drop-out rate of $2 \%$. The majority of respondents were female $(63 \%)$, under the age of 23 (75\%), and were not on the four year graduate-entry programme (13\%) or three year dental programme for medical graduates (1\%). Only $5 \%$ were aged 30 years or above. The demographics of those attending broadly matched those of the whole student body. There was no further follow up of students who had not attended lectures. Students reported starting to wear loupes in year three of the programme and this was more frequent amongst those in latter stages of the programme. There was no difference in the self-reported weekly frequency of exercise between different year groups (chi-squared test, $\mathrm{P}=0.478$ ). However levels of self-reported fitness did show a tendency to improve as students become more senior, although this did not quite reach statistical significance (chisquared test, $\mathrm{P}=0.069$ ).

\section{Pain}

The prevalence and characteristics of pain reported are shown in Tables 2 and 3. Overall, $79 \%$ of respondents reported experiencing one of neck, upper back or lower back pain with $42 \%$ of these experiencing this pain for 30 or more days in the past year. Lower back pain was reported as both the most common problem (54\% of respondents) and was most frequently chosen as the single worst area of pain ( $48 \%$ of those experiencing pain in any site). Thirty-sxi percent of respondents reported pain lasting for at least four hours, and $20 \%$ reported that this pain occurred on at least $50 \%$ of all days. The mean 'average pain intensity' VAS score was $3.81 / 10(\mathrm{sd}=1.75)$ and the mean 'worst pain intensity' VAS score was $5.56 / 10(\mathrm{sd}=2.10)$. Female respondents reported a statistically significant higher incidence of neck pain (58\% versus $37 \%, \mathrm{P}<0.001$ ) as well as higher 'average pain intensity' VAS scores (mean 4.02, sd 1.82 versus $3.43 \mathrm{sd} 1.55, \mathrm{P}=0.012$ ). Perceived overall and peak pain VAS scores did not significantly vary between student year groups.

There was a tendency towards greater reported impact both of operative procedures on pain levels and of pain on performance of operative procedures for more senior compared to more junior students (KruskallWallis tests, $\mathrm{P}=0.0001$ ), although this pattern was seen more clearly when considering the impact of pain on dental procedures. There were additionally weak positive, but statistically

Table 1 Gender, use of loupes, self-reported exercise frequency and fitness of study participants, overall and by year group, identified as for example BDS1 is year 1 of programme

\begin{tabular}{|c|c|c|c|c|c|c|c|}
\hline \multirow{2}{*}{\multicolumn{2}{|c|}{ Sociodemographic variables }} & \multirow{2}{*}{$\begin{array}{l}\text { Respondents, } \\
\text { N (\%) }\end{array}$} & \multicolumn{5}{|c|}{ Respondents per year group, N (\%) } \\
\hline & & & BDS 1 & BDS 2 & BDS 3 & BDS 4 & BDS 5 \\
\hline \multicolumn{2}{|l|}{ Male } & $145(37)$ & 32 & 35 & 16 & 29 & 33 \\
\hline \multicolumn{2}{|l|}{ Female } & $245(63)$ & 58 & 48 & 30 & 55 & 54 \\
\hline \multicolumn{2}{|l|}{ Total } & 390 & 90 & 83 & 46 & 84 & 87 \\
\hline \multicolumn{2}{|l|}{ Use of loupes } & $49(12.6)$ & 0 & 0 & $10(22)$ & $13(15)$ & $26(30)$ \\
\hline \multirow{4}{*}{$\begin{array}{l}\text { Self-reported exercise } \\
\text { (days per week) }\end{array}$} & 0 & $65(17)$ & $14(15)$ & $14(17)$ & $6(13)$ & $13(15)$ & $18(21)$ \\
\hline & 01-Mar & $202(52)$ & $51(57)$ & $41(49)$ & $21(46)$ & $43(51)$ & $46(53)$ \\
\hline & 03-May & $96(24)$ & $21(23)$ & $22(26)$ & $12(26)$ & $25(30)$ & $16(18)$ \\
\hline & 05-Jul & $27(7)$ & $4(4)$ & $6(7)$ & $7(15)$ & $3(4)$ & $7(8)$ \\
\hline \multirow{3}{*}{ Self-reported fitness } & Poor & $34(9)$ & $5(6)$ & $13(16)$ & $2(4)$ & $7(8)$ & $7(7)$ \\
\hline & Moderate & $222(57)$ & $61(68)$ & $44(53)$ & $23(50)$ & $52(62)$ & $42(49)$ \\
\hline & Good & $133(34)$ & $24(27)$ & $26(31)$ & $21(46)$ & $25(30)$ & $37(44)$ \\
\hline
\end{tabular}


significant, correlations between the worse reported VAS score and both the impact of pain on procedure performance $(\mathrm{R}=0.1482$, $\mathrm{P}=0.0093)$ and on the impact of procedure performance on pain $(\mathrm{R}=0.211, \mathrm{P}=0.0002)$.

The mean age of reported pain onset was 19 years for each of the problems studied, with a standard deviation of 3.5 (neck) to 3.9 (lower back) years. This does suggest that some students may be experiencing these problems before learning operative dental techniques although the age of onset does coincide with early operative teaching.

\section{Coping strategies used}

The most commonly used strategy for dealing with pain was daily stretching (55.7\% of respondents, of which $73 \%$ were female), and there were statistically significant increased 'average pain intensity' $(\mathrm{P}=0.096)$ and 'worst pain intensity' $(\mathrm{P}=0.001)$ VAS scores for those students attempting to use daily stretching as a means of dealing with the pain. Eighteen percent of respondents had sought professional help to manage pain. Variations in pain scores by coping strategy are shown in Table 4 . Weights were used more frequently by male students ( $46 \%$ versus $10 \%, \mathrm{P}<0.001$ chi squared test), and yoga more often by female students (23\% versus $13 \%, \mathrm{P}=0.05$ chi squared test). Respondents who reported using these strategies had higher VAS scores than those who did not.

The $23 \%$ of students who reported using weights as a coping strategy reported significantly higher 'worst pain intensity' VAS scores (mean 6.03 sd $1.87, \mathrm{P}=0.043$ versus mean $5.42 \mathrm{sd}$ 2.15, Mann-Whitney test).

A total of $12.6 \%$ of respondents used loupes, with $51 \%$ of these using a light attached to their loupes. The percentage of students using loupes increased from $0 \%$ in BDS 1 to 30\% in BDS 5.

\section{Multivariate analysis of factors associated with pain}

An attempt was made to use logistic regression to determine which of the recorded factors had an impact on the prevalence of reported pain when considered in a combined model. However this failed to show any consistent further useful findings beyond those relationships already identified.

\section{Discussion}

In this cross-sectional study there was a high prevalence of musculoskeletal pain in the upper back, lower back and neck regions of

Table 2 Prevalence, relative severity and impact of pain episodes, identified as for example BDS1 is year 1 of programme

\begin{tabular}{|c|c|c|c|c|c|c|c|}
\hline & & \multirow{2}{*}{ All, N (\%) } & \multicolumn{5}{|c|}{ Year group, N (\%) } \\
\hline & & & BDS 1 & BDS 2 & BDS 3 & BDS 4 & BDS 5 \\
\hline \multirow{4}{*}{$\begin{array}{l}\text { Prevalence of pain } \\
\text { (no. of respondents, \%) }\end{array}$} & Neck & $195(50)$ & $30(33)$ & $41(49)$ & $30(65)$ & $49(58)$ & $45(51)$ \\
\hline & Upper back & $169(43)$ & $33(37)$ & $30(36)$ & $19(41)$ & $45(54)$ & $42(48)$ \\
\hline & Lower back & $209(54)$ & $38(42)$ & $42(51)$ & $24(52)$ & $52(62)$ & $53(61)$ \\
\hline & Any area of pain & $307(79)$ & $55(61)$ & $62(74)$ & $38(83)$ & $78(93)$ & $74(85)$ \\
\hline \multirow{3}{*}{$\begin{array}{l}\text { Worst area of pain } \\
\text { (no. of respondents) } \\
\text { (\% of those experiencing pain } \\
\text { in any site) }\end{array}$} & Neck & $78(25)$ & $11(20)$ & $18(29)$ & $16(42)$ & $18(23)$ & $15(20)$ \\
\hline & Upper back & $83(27)$ & $15(27)$ & $15(24)$ & $8(21)$ & $25(32)$ & $20(27)$ \\
\hline & Lower back & $146(48)$ & $29(53)$ & $29(47)$ & $14(37)$ & $35(45)$ & $39(53)$ \\
\hline Mean (standard deviation) & Average pain intensity & $3.8(1.8)$ & $3.9(1.7)$ & $3.5(1.7)$ & $3.4(1.4)$ & $4.2(1.8)$ & $3.9(1.8)$ \\
\hline Pain VAS scores & Worst pain intensity & $5.7(2.1)$ & $5.7(2.3)$ & $5.1(2.1)$ & $5.0(1.7)$ & $5.7(2.1)$ & $6.0(2.1)$ \\
\hline \multirow{2}{*}{$\begin{array}{l}\text { Mean (standard deviation) } \\
\text { impact VAS scores }\end{array}$} & Impact of pain on dental procedures & $4.3(3.1)$ & $0(0)$ & $3.8(2.6)$ & $4.6(2.6)$ & $6.3(2.3)$ & $5.8(2.4)$ \\
\hline & Impact of dental procedures on pain & $3.3(2.7)$ & $0(0)$ & $3.5(2.2)$ & $3.4(2.5)$ & $4.9(2.3)$ & $4.0(2.5)$ \\
\hline
\end{tabular}

Table 3 Duration and recent experience of episodes, identified as for example BDS1 is year 1 of programme

\begin{tabular}{|c|c|c|c|c|c|c|c|}
\hline & & \multirow{2}{*}{ All, N (\%) } & \multicolumn{5}{|c|}{ Year group, $\mathrm{N}(\%)$} \\
\hline & & & BDS 1 & BDS 2 & BDS 3 & BDS 4 & BDS 5 \\
\hline \multirow{6}{*}{$\begin{array}{l}\text { Duration of pain over last year } \\
\text { (no. of respondents, \%) }\end{array}$} & Neck: up to 30 days & $166(43)$ & $30(33)$ & $36(49)$ & $26(65)$ & $40(58)$ & $34(51)$ \\
\hline & Neck: over 30 days & $28(7)$ & $3(9)$ & $3(9)$ & $4(9)$ & $9(11)$ & $9(10)$ \\
\hline & Upper back: up to 30 days & $117(30)$ & $25(37)$ & $21(25)$ & $12(41)$ & $30(36)$ & $29(33)$ \\
\hline & Upper back: over 30 days & $47(12)$ & $7(8)$ & $7(8)$ & $7(26)$ & $15(18)$ & $11(13)$ \\
\hline & Lower back: up to 30 days & $149(38)$ & $26(29)$ & $32(39)$ & $19(41)$ & $36(43)$ & $36(41)$ \\
\hline & Lower back: over 30 days & $54(14)$ & $10(11)$ & $9(11)$ & $4(9)$ & $16(19)$ & $15(17)$ \\
\hline \multirow{3}{*}{$\begin{array}{l}\text { Pain experienced in the last } \\
\text { week } \\
\text { (no. of respondents, \%) }\end{array}$} & Neck & $70(18)$ & $14(16)$ & $9(11)$ & $13(28)$ & $18(21)$ & $16(18)$ \\
\hline & Upper back & $77(20)$ & $14(16)$ & $8(10)$ & $12(26)$ & $25(30)$ & $18(21)$ \\
\hline & Lower back & $85(22)$ & $17(19)$ & $13(16)$ & $11(24)$ & $24(29)$ & $20(23)$ \\
\hline
\end{tabular}


Table 4 Reported pain intensity by various coping strategies

\begin{tabular}{l|l|l|l|l|l|l|l} 
& \multicolumn{3}{|c}{ Overall pain VAS score mean (sd) } & \multicolumn{3}{c}{ Worst pain VAS score mean (sd) } \\
\cline { 2 - 8 } & Strategy used & Not used & P & Strategy used & Not used & P \\
\hline Stretching N = 171 & $3.97(1.71)$ & $3.60(1.77)$ & 0.052 & $5.94(2.00)$ & $5.09(2.14)$ & 0.001 \\
\hline Yoga N = 59 & $4.15(1.81)$ & $3.73(1.72)$ & 0.128 & $6.16(2.23)$ & $5.42(2.05)$ & 0.023 & 0.043 \\
\hline Weights N = 72 & $3.89(1.58)$ & $3.78(1.80)$ & 0.513 & $6.03(1.87)$ & $5.42(2.15)$ & $5.54(2.10)$ & 0.61 \\
\hline Loupes N = 33 & $3.71(1.59)$ & $3.82(1.77)$ & 0.777 & $5.73(2.17)$ & & \\
\hline
\end{tabular}

undergraduate dental students. The reported prevalence of musculoskeletal pain in this study $(79 \%)$ is in line with similar studies for both dentists, ranging from $64 \%-93 \%,{ }^{1,5,11,12}$ and dental students, ranging from $46 \%-86 \% .^{13-15}$ Rising et al. ${ }^{13}$ reported that there was a significant year-by-year increase of a perception that dental procedures aggravate musculoskeletal pain amongst dental students from California. These findings are consistent with those found in our study, which also suggests that there is a similar pattern in the perceived influence of the pain itself on operative procedures. Female students made up $63 \%$ of respondents in this study, compared to an overall percentage of $58.4 \%$ of students in the undergraduate dental student body. We therefore feel that in terms of gender this is in fact a representative population.

The modified Nordic questionnaire used in this study is considered to be an acceptable method to measure the prevalence of musculoskeletal pain, ${ }^{5}$ and has been used in a number of other similar studies. ${ }^{15-17}$ As participants of this study provided self-reported information there is the potential for bias, and it could be suggested that more accurate results could be obtained by using physical examinations and assessments. ${ }^{12}$ However, these may be limited to assessment of posture, functional movement or asymmetry, which may not reflect the day-to-day impact of these problems. Alternatives would be the use of established scales that record functional or daily living impairment, such as the Roland-Morris scale for back pain and disability ${ }^{18,19}$ or the Neck Disability Index..$^{20}$ The high response rate for this study is good, but it is tempered by the fact that it still only involved approximately $50 \%$ of the whole undergraduate student body, which suggests the possibility of selection bias in the results. However, there is no reason to believe that those who have attended lectures are more likely to have experienced musculoskeletal pain, or vice versa.

This study identified lower back pain as being both the most prevalent area of musculoskeletal pain (54\%), and the most commonly reported worst area of pain (48\%). This is in line with a number of other studies. ${ }^{16,22,23}$ This finding is significant as highlighted in a study by Myers \& Myers $^{24}$ which showed that the main health complaint amongst dentists - causing chronic concern, medical care and leading to absenteeism - was lower back pain, quoting a slightly higher prevalence of $62 \%$. A study by Rudcrantz et al. ${ }^{2}$ found that more than $50 \%$ of Swedish dentists had experienced lower back pain in the last year, which is slightly higher than the $38 \%$ found in our study. Interestingly, the study by Rudcrantz et al. also highlighted that the pain intensity experienced by younger dentists was greater than that of older dentists. This inverse relationship between age and musculoskeletal pain has also been noted in a number of other studies, ${ }^{11,16,25}$ with a suggested hypothesis being that more experienced dentists have developed techniques and adopted their work posture to minimise the impact of musculoskeletal pain. ${ }^{4}$ An alternative explanation in this population is that more senior students may have been less keen to report pain since they felt that it may have been associated with repeated poor posture whilst treating patients. It is also interesting to note that the relative impact of pain was greater for more senior students, even though the actual reported pain scores themselves did not vary. This may be a reflection of students potentially being exposed to more repeated episodes of physical discomfort as the clinical component of their programme increased with time, and the likely increased duration of each clinical session. It is notable that, in this population, pain levels tended to be higher in those who had instigated attempts at managing their problem. Therefore, a potential solution to minimise the issue of musculoskeletal pain amongst young dentists could be to accelerate the process of improving work posture and, relevant to the demographic of this study, this could perhaps be achieved by more actively developing this during undergraduate dental training.

There are a number of different approaches which have previously been suggested to prevent the onset and progression of occupational musculoskeletal pain, including improving physical fitness, improving work posture, regular stretching and health promotion. ${ }^{26,27}$

Epidemiological studies have shown that high fitness levels have been correlated with positive back health. ${ }^{28-30}$ Due to its ability to improve musculoskeletal and cardiovascular function, physical exercise may be useful for improving back function and preventing development of work-related musculoskeletal disorders, this has been strongly suggested from prospective studies in medical literature. ${ }^{29,31}$ Some studies suggest that ergonomic advice on improving physical activity should be offered before the individual begins his or her working career or during education. ${ }^{32,33} \mathrm{~A}$ study from Peros et al. ${ }^{34}$ showed that the introduction of a physical fitness program into the dental curriculum, involving 90 minutes of cardiovascular activity per week, had a positive impact on lower back pain amongst final-year dental students in Croatia.

Nutalapati et al. ${ }^{35}$ suggested a number of different strategies to limit musculoskeletal problems amongst dentists by improving surgery ergonomics. These strategies involve proper chair side positioning, ${ }^{36}$ avoidance of prolonged static postures or excessive twisting motions, and periodic breaks and stretching. All these strategies could be taught under a wider health promotion preventive program as part of an undergraduate curriculum. This is effectively part of a larger ongoing strategy emphasising the overall benefits of continuing to work, using functional adaptations wherever possible. ${ }^{37}$

In this study, $30 \%$ of students in their final year used loupes as a form of magnification, which matches very favourably to wider demographic data suggesting that $26 \%$ of dentists use magnification aids, and a positive correlation showing that older dentists were more likely to 
use loupes. ${ }^{38}$ This suggests that there may be a trend of increasing loupe use amongst the next generation of young dentists. Increased use of loupes may have a role to play in preventing or managing musculoskeletal issues in this cohort. This may be favourable as suggested by James and Gilmour ${ }^{39}$ who comment that the appropriate use of magnification, in the form of dental loupes and microscopes, facilitates a more upright posture and has been shown in some cases to diminish or eliminate chronic back and neck pain.

\section{Conclusion}

The results of this study demonstrate that neck and back pain constitute a major problem in the daily lives of undergraduate dental students who were surveyed. Whilst this study does have some limitations, these findings are in line with previous reports in dentist and dental student cohorts. These findings suggest that education and support in self-care in this regard may be an important and valuable addition to the curriculum to improve the health of dental students, and could have benefits in managing current problems as well as in preventing problems in later life. Assessments of the effectiveness of possible interventions are, however, needed to confirm this.

1. Marshall E D, Duncombe L M, Robinson R Q et al. Musculoskeletal symptoms in New South Wales dentists. Aust Dent J 1997: 42: 240-246.

2. Rundcrantz B, Johnsson B, Moritz L. Cervical pain and discomfort among dentists. Epidemiological, clinical and therapeutic aspects. Swed Dent J 1990; 14: 71-80.

3. Valachi B, Valachi K. Mechanisms leading to musculoskeletal disorders in dentistry. J Am Dent Assoc 2003; 134: 1344-1350.

4. Leggat P A, Kedjarune U, Smith D R. Occupational health problems in modern dentistry. Ind Health 2007; 45: 611-621.
5. Hayes M, Cockrell D, Smith DR. A systematic review of musculoskeletal disorders among dental professionals. Int J Dent Hyg 2009; 7: 159-165.

6. Kuorinka I, Jonsson B, Kilborn A et al. Standardised Nordic questionnaires for the analysis of musculoskeletal symptoms. Applied Ergonomics 1987: 18: 233-237.

7. Bergqvist $U$, Wolgast $E$, Nilsson $B$ et al. The influence of VDT work on musculoskeletal disorders. Ergonomics 1995; 38: 754-762.

8. Palmer K, Smith G, Kellingray S et al. Repeatability and validity of an upper limb and neck discomfort questionnaire: the utility of the standardized Nordic questionnaire. Occup Med (Lond) 1999; 49: 171-175.

9. Cook C, Burgess-Limerick R, Chang S W. The prevalence of neck and upper extremity musculoskeletal symptoms in computer mouse users. Int J Ind Ergon 2000; 26: 347-356.

10. Porter J M, Gyi D E. The prevalence of musculoskeletal troubles among car drivers. Occup Med (Lond) 2002; 52: 4-12.

11. Chowanadisai S, Kukiattrakoon B, Yapong B et al. Occupational health problems of dentists in southern Thailand. Int Dent J 2000: 50: 36-40.

12. Akesson I, Johnsson B, Rylander L et al. Musculoskeletal disorders among female dental personnel - clinical examination and a 5 -year follow-up study of symptoms. Int Arch Occup Environ Health 1999; 72: 395-403.

13. Rising D W, Bennett B C, Hursh K et al. Reports of body pain in a dental student population. J Am Dent Assoc 2005; 136: 81-86.

14. Marcellos M, Youssef S, Luca C et al. Upper body musculoskeletal symptoms in Sardinian dental student. J Can Dent Assoc 2004; 70: 306-310.

15. Adnan F K, Ayfer T, Cankat T D et al. Musculoskeletal disorders in left-and right-handed Turkish dental students. Int J Neurosci 2005; 115: 255-266.

16. Finsen L, Christensen H, Bakke M. Musculosceletal disorders among dentists and variation in dental work. Appl Ergon 1998; 29: 119-25.

17. Anton D, Rosecrance J, Merlino L et al. Prevalence of musculoskeletal symptoms and carpal tunnel syndrome among dental hygienists. Am J Ind Med 2002; 42: 248-257.

18. Roland M O, Morris RW. A study of the natural history of back pain. Part 1: Development of a reliable and sensitive measure of disability in low back pain. Spine 1983; 8: 141-144.

19. Roland M O, Morris RW. A study of the natural history of back pain. Part II: Development of guidelines for trials of treatment in primary care. Spine 1983; 8: 145-150.

20. Vernon, H, Mior S. The Neck Disability Index: A study of reliability and validity. J Manip Phys Ther 1991; 14: 409-415.

21. Ylipaa V, Arnetz B B, Preber H. Factors that affect health and well-being in dental hygienists; a comparison of Swedish dental practices. J Dent Hyg 1999; 73: 191-199.
22. Szymanska J. Disorders of the musculoskeletal system among dentists from the aspect of ergonomics and prophylaxis. Ann Agric Environ Med 2002; 9: 169-173.

23. Ratzon NZ. Musculoskeletal symptoms among dentists in relation to work posture. Work 2000; 15: 153-158.

24. Myers H L, Myers LB. 'It's difficult being a dentist': stress and health in the general dental practitioner. Br Dent J 2004; 197: 89-93.

25. Leggat P.A, Smith D R. Musculoskeletal disorders self-reported by dentists in Queensland, Australia. Austral Dent J 2006; 51: 324-327.

26. Feldman D E, Shrier I, Rossignol M, Abenhaim L. Work is a risk factor for adolescent musculoskeletal pain. J Occ Environ Med 2002; 44: 956-961.

27. Chang BJ. Ergonomic benefits of surgical telescope systems: selection guidelines. J Calif Dent Assoc 2002; 30: 161-169.

28. Suni J H, Oja P, Miilunpalo SI, Pasanen M E, Vuori I M, Bos K. Health-related fitness test battery for adults: associations with perceived health, mobility, and back function and symptoms. Arch Phys Med Rehabil 1998; 79: 559-569.

29. Croft P R, Papageorgiou A C, Thomas E, Macfarlane G J, Silman AJ. Short-term physical risk factors for new episodes of low back pain: prospective evidence from the South Manchester Back Pain Study. Spine 1999; 24: 1556-61.

30. Rainville J, Hartigan C, Martinez E, Limke J, Jouve C, Finno M. Exercise as a treatment for chronic low back pain. Spine J 2004; 4: 106-115.

31. Harreby M, Hesselsoe G, Kjer J, Neergaard K. Low back pain and physical exercise in leisure time in 38-year-old men and women: a 25 -year prospective cohort study of 640 school children. Eur Spine J 1997: 6: 181-186.

32. Proper KI, Koning M, Van der Beek AJ. The effectiveness of worksite physical activity programs on physical activity, physical fitness, and health: a critical review. Clin J Sport Med 2003: 13: 106-117.

33. Karjalainen $\mathrm{A}$. The changing spectrum of occupational diseases.Duodecim 2003; 119: 1303-1304.

34. Peros K, Vodanovic M, Mestrovic S, Rosin-Grget K, Valic $M$. Physical fitness course in the dental curriculum and prevention of low back pain J Dent Educ 2011; 75: 761-767.

35. R Nutalapati, R Gaddipati, H Chitta, M Pinninti, R Boyapati. Ergonomics in dentistry and the prevention of musculoskeletal disorders in dentists. Internet J Occl Health. 2009; 1.

36. Valachi B, Valachi K. Preventing musculoskeletal disorders in clinical dentistry: strategies to address the mechanisms leading to musculoskeletal disorders. J Am Dent Assoc. 2003; 134: 1604-1612.

37. The costs and benefits of active case management and rehabilitation for musculoskeletal disorders . Health \& Safety Executive 2006 Research Report 493.

38. Burke F J, Wilson N H, Cheung S W, Brunton PA. Contemporary dental practice in the UK: demographic data and practising arrangements. Br Dent J. 2005; 198: 39-43.

39. James T, Gilmour A S. Magnifying loupes in modern dental practice: an update. Dent Update. 2010; 37: 633-636

This work is licensed under a Creative Commons Attribution-NonCommercial-No Derivs 4.0 International License. The images or other third party material in this article are included in the article's Creative Commons license, unless indicated otherwise in the credit line; if the material is not included under the Creative Commons license, users will need to obtain permission from the license holder to reproduce the material. To view a copy of this license, visit http://creativecommons.org/licenses/by-nc-nd/4.0/ (c) The Author(s) 2016 